\title{
A Photographic Technique for Repeated Mapping of Rangeland Plant Populations in Permanent Plots
}

\author{
M.K. OWENS, H.G. GARDINER, AND B.E. NORTON
}

\begin{abstract}
A lightweight aluminum photograph stand has been developed to record vegetation in permanent plots. At a camera height of $7 \mathrm{~m}$ the plot size is $14 \mathrm{~m}^{2}$ when using a $70 \mathrm{~mm}$ camera with an $80 \mathrm{~mm}$ lens. Minor errors were detected when testing the accuracy of the stand. This stand will be useful for obtaining a record of permanent plots for many different types of research studies.
\end{abstract}

Measurements of successional change, or vegetation trend, are difficult to quantify and easy to misinterpret. Trend is usually estimated using such variables as phytomass, cover or frequency. Major changes in the plant community can occur before any of these variables could detect it (Gardiner and Norton 1983, West 1983). Replacement of one species by another (succession), and the births and deaths of individuals, can easily be detected by sampling permanent plots at regular intervals. With such data, the population dynamics of a species can be estimated, and interpretations of range trends are enhanced. Unfortunately, the two most common techniques available for obtaining such data, the pantograph and chart mapping, are time consuming and often inaccurate. Very few plots are recorded and they are typically only $1 \mathrm{~m}^{2}$ in area. In semiarid rangelands, the small sample size and limited area covered are usually inadequate for reliable records of changes in most species. One notable exception is the data set collected on 9.3 $\mathrm{m}^{2}$ chart-quadrats at the Desert Experimental Range, Utah (Norton 1978). Other techniques for sampling permanent plots are therefore necessary.

Low level aerial photography (Hacker 1978) provides a possible mapping alternative. Many problems, however are associated with small-scale format: different scales due to different aircraft altitudes and uncontrolled distortions caused by aircraft tilt, wind, and site slope. Maps produced in this manner may not be suffi-

Authors were principal research technician, graduate research assistant and associate professor, respectively, with the Range Science Department, Utah State University, Logan, Utah 84322 at the time of the research.

H.G. Gardiner's current address is Agricultural Advisor, Rangeland Management Branch, Western Australian Department of Agriculture, Jarrah Rd., South Perth, W.A. 6151 .

Manuscript accepted September 9, 1984. ciently reliable for demographic studies and are generally restricted to low shrublands. Tree canopy cover may obscure essential components of the vegetation, and small individuals, particularly seedlings, are difficult to map accurately. The typical result of sequential recordings of a single plot are assorted photographs of different scales and clarity.

Another possibility is to use a stand to hold a camera for groundlevel photography. Cooper (1924) reported devising an oak stand that would hold a $5 \times 7$ camera $1.8 \mathrm{~m}$ above the ground. Unfortunately, the plot accommodated by this stand was only $1 \mathrm{~m}^{2}$. Modifications were made throughout subsequent years to either raise or lower the camera height. Camera height has ranged from a low of $1.2 \mathrm{~m}$ (Ratliff and Westfall 1973) to a high of $3.5 \mathrm{~m}$ (Goodwin and Walker 1972). Corresponding plot sizes ranged from $0.09 \mathrm{~m}^{2}$ to 14 $\mathrm{m}^{2}$, respectively. Only in one photographic method has plot size been sufficiently large to study semiarid vegetation. Goodwin and Walker (1972) developed a photograph standing using a boom rather than the traditional tripod. The camera could be raised to a much greater height, approximately $3.5 \mathrm{~m}$. Using a wide angle lens on a $35 \mathrm{~mm}$ camera resulted in a large plot size, but the $35 \mathrm{~mm}$ format limits the clarity of the photograph.

\section{The Photograph Stand}

Constructed from lightweight box aluminum, a portable stand has been developed for use in semiarid rangelands (Fig. 1). Using a boom apparatus rather than a tripod allows the camera height above ground to be increased to as much as $7 \mathrm{~m}$. At the maximum height a $3.5 \times 4 \mathrm{~m}$ plot is obtained. A plot of this size $\left(14 \mathrm{~m}^{2}\right)$ is adequate for studying most semiarid grass and shrub species populations.

In order to consistently re-photograph the same plot, anchor pins were necessary. Three pieces of $1.2 \mathrm{~m}$ long $15.8 \mathrm{~mm}$ concrete reinforcing bar were driven into the ground at every plot. Guide holes in the frame fit over the anchors so the base position is identical at each sampling time. Slight irregularities of the soil 


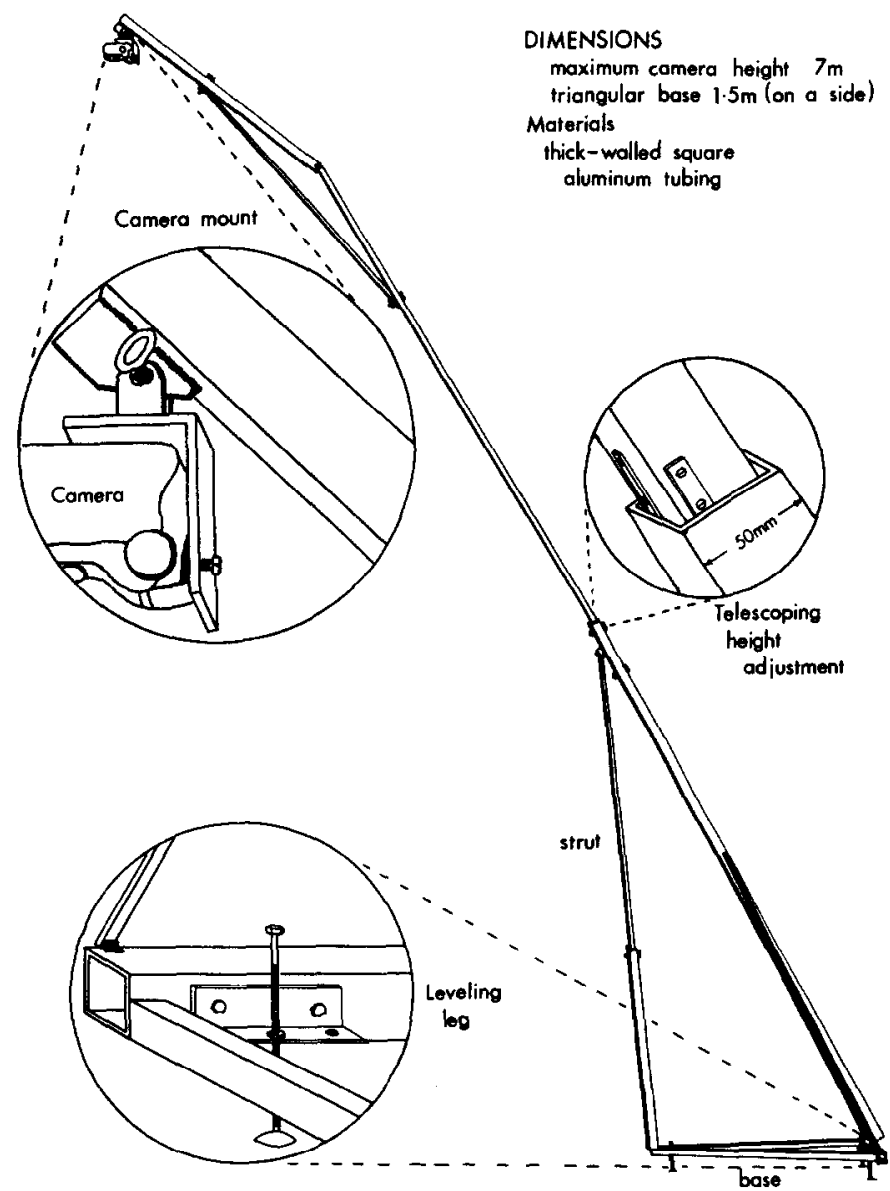

Fig. 1. A schematic of the portable photograph stand.

surface seriously affect the repeatability of positioning the camera. Therefore, small leveling legs were installed adjacent to the guide holes so the frame could be leveled before each photograph.

Both a $35 \mathrm{~mm}$ and a $70 \mathrm{~mm}$ camera were tested with the stand. The $35 \mathrm{~mm}$ camera with a $28 \mathrm{~mm}$ lens resulted in the largest plot size $(6 \times 9 \mathrm{~m})$ but the photograph was not sufficiently clear to accurately portray small individuals. Even with a $50 \mathrm{~mm}$ lens clarity was not sufficient for accurate, repeatable mapping. The 70 $\mathrm{mm}$ camera with a $80 \mathrm{~mm}$ lens resulted in a large plot $(3.5 \times 4 \mathrm{~m})$ and the resolution of the photograph was high. Ektachrome film was used because of the ease of development.

Color transparencies were developed of each plot photographed. The transparencies were then back-projected onto a piece of glass and the outline of each plant was traced onto a piece of paper. The traced map was then compared to the actual plot for authenticity.

\section{Results}

This stand is currently being used in a plant population study at the Tintic Research Site, Tintic, Utah. During the spring of 1983, seventy plots were photographed, and data were obtained as previously described. A total of 10,256 individual plants were mapped with only minor error.
The most common error was failing to recognize in the photograph, and trace on the map, some plants that were in the plot. Approximately $13 \%$ (1,300 individuals) of the total were missed this way. Small plants and new seedlings commonly occurred beneath the canopies of the larger plants. Naturally a vertical photograph could not detect those plants. For this reason, ground verification is essential. Only 15 "plants" $(0.01 \%)$ were traced from the transparency when in fact they were artifacts.

When the plots were re-visited during the fall of 1983 , one hundred percent of the plants mapped during the spring could be relocated. In every case either a live plant or a dead stem could be found. Such precision is essential for studying plant population dynamics. In addition, 398 plants, representing a $4 \%$ error, were mapped for the first time during the fall although they were sufficiently large to have been present at the spring recording time.

The amount of time required per plot was highly dependent on the number of plants in the plot $(r=0.985)$. Plot establishment and photographing averaged 45 minutes per plot. Every plot, regardless of the plant density, required this much time. Photographing time was less than 5 minutes per plot, excluding travel time between plots. Tracing the transparencies onto the map averaged 15 minutes per plot, although variation was high. Ground verification time ranged from 10 minutes for a plot with 119 individuals to 70 minutes for a plot with 666 individuals. Again, the amount of time required was dependent on the complexity of the vegetation structure as well as on the number of individuals.

\section{Conclusions}

The use of photographs has been recognized as a viable data collection procedure for a long time; however, problems of small plot size, clarity and repeatability have often presented insurmountable obstacles to using this technique. These problems can be alleviated by increasing plot and film size. Be securing a portable aluminum stand to permanent anchors, a plot can be exactly relocated. Such an accurate, repeatable technique will be a valuable tool in grazing behavior research, plant population studies, and in range trend recordings.

\section{Literature Cited}

Cooper, W.S. 1924. An apparatus for photographic recording of quadrats. J. Ecol. 12:317-321.

Gardiner, H.G., and B.E. Norton. 1983. Do traditional methods provide a reliable measure of range trend?p. 618-622. In: J.F. Bell and T. Atterbury (eds.) Proc. Int. Conf. on Renewable Resource Inventories for Monitoring Changes and Trends. August 15-19, 1983. Oregon State Univ., Corvallis.

Goodwin, W.F., and J. Walker. 1972. Photographic recording of vegetation in regenerating woodland. Woodland Ecol. Unit, Commonwealth Scientific and Ind ustrial Research Organization, Canberra City, Australia, Tech. Comm. 1.

Hacker, R.B. 1978. Use of large scale aerial photographs for ecological studies in a grazed, arid ecosystem. p. 1895-1908. In: Proc. 12th Int. Symp. on Rem. Sens. of Environment. Environmental Res. Inst. of Mich. and Nat. Res. Manage. Centre, Phillipines.

Norton, B.E. 1978. The impact of sheep grazing on long-term successional trends in the salt-desert shrub vegetation of southwestern Utah. p. 610613. In: First Int. Rangeland Cong. Denver, Colo.

Ratliff, R.D., and S.E. Westfall. 1973. A simple stcreographic technique for analyzing small plots. J. Range Manage. 26:147-148.

West, N.E. 1983. Choice of vegetation variables to monitor range condition and trend. p. 636-639. In: J.F. Bell and T. Atterbury (eds.) Proc. Int. Conf. on Renewable Resource Inventories for Monitoring Changes and Trends. August 15-19, 1983. Oregon State Univ., Corvallis.

Wimbush, D.J., M.D. Barrow and A.B. Costin. 1967. Color stereophotography for the measurement of vegetation. Ecology. 48:150-152. 